\title{
Hydrological Impacts of Climate Change Simulated by HIMS Models in the Luanhe River Basin, North China
}

\author{
Yan Jiang $•$ Changming Liu $\cdot$ Xuyong Li
}

Received: 26 May 2014 / Accepted: 7 November 2014 /

Published online: 28 November 2014

(C) Springer Science+Business Media Dordrecht 2014

\begin{abstract}
This paper applied a HIMS (hydroinformatic modeling system) model to simulate streamflow in the Luanhe River Basin. This model was compared with SIMHYD and XAJ models for eight sub-basins of the Luanhe River. The results showed HIMS model performed better than SIMHYD and XAJ models, in these areas. We then investigated the streamflow response to climate changes in the different sub-basins. Twenty hypothetical climate change scenarios (perturbed temperatures and precipitation) were used to test the sensitivity of HIMS model simulated annual and mean monthly streamflow. Our results demonstrated that: (i) the annual streamflow was positively related to precipitation, and there was a negative relationship between streamflow and temperature for all the eight sub-basins; (ii) in all sub-basins, the relationship of annual streamflow change to precipitation change was highly non-linear, but the relationship of annual streamflow change with temperature change was approximately linear; (iii) the annual streamflow response to precipitation change was more sensitive when increasing than decreasing; (iv) the annual streamflow response to climate change was more sensitive in the Xingzhouhe River sub-basin, followed by the Wuliehe River sub-basin, and the Sahe River sub-basin was least sensitive; (iv) there were few differences in inner-streamflow response to climate change in the Laoniuhe, Yimatuhe, and Yixunhe Rivers. But for other rivers, when the temperature changed, larger streamflow differences happened in winter and summer; when the precipitation decreased or was unchanged, the larger differences happened in winter months, and when the precipitation increased, larger differences happened in winter and summer.
\end{abstract}

Keywords HIMS rainfall-runoff model $\cdot$ Semi-arid catchment · Climate change

Y. Jiang $(\bowtie) \cdot X$. Li

State Key Laboratory of Urban and Regional Ecology, Research Center for Eco-Environmental Sciences, Chinese Academy of Sciences, Beijing 100085, China

e-mail: yanjiang@rcees.ac.cn

C. Liu

Institute of Geographic Sciences and Natural Resources Research, Chinese Academy of Sciences, Beijing 100101, China 


\section{Introduction}

Climate change is now widely recognized as one of the major environmental problems (Bates et al. 2008). Scientific investigations into global climate change and its consequences began to increase in the 1980s (Muzik 2002). It is understood that the global climate system has changed on both regional and global scales over the last century, and will continue in the near future (IPCC 2001). Due to changes of atmospheric circulation and hydrologic cycle, increasing global mean surface temperature will change precipitation and atmospheric moisture. This will, in turn, affect ecological, social, and economic systems (Dibike and Coulibaly 2005; Singh et al. 2006). Therefore, it is important to study the impacts of climate change on hydrology and water resource systems, and provide a basis for important decisions regarding flood control, drought resistance, and water resource use.

The hydrological cycle is very sensitive to changes in climate, particularly in arid and semiarid regions. In the drier climate, the hydrological cycle is the more sensitive to climate changes (Peng and $\mathrm{Xu}$ 2010). Water resources in semi-arid regions are strongly affected by precipitation and temperature. Many studies have been conducted investigating the impact of climate change on hydrological processes in semi-arid regions. In recent years, researchers have undertaken modeling analyses for these processes. In the Haihe River basin, a semi-arid region in the north China, three climate change scenarios were used to derive a VIC-3L model to address the influences of climate variables on streamflow (Yuan et al. 2005). In the Okanagan Basin, a snow-driven semi-arid basin located in the southern interior region of British Columbia, the UBC Watershed Model was used to model the hydrologic response to climate change based on the CGCM2, CSIROMk2, and HadCM3 scenarios (Merritt et al. 2006). Zhang et al. (2007) applied the SWAT model to evaluate the effect of climate change on future streamflow volume in the Luohe River basin, a semi-arid region. In the headwater catchment of the Yellow River basin, the SWAT model was also used to evaluate the impacts of climate change on the mean annual streamflow (Xu et al. 2009). Under alternative climate change scenario, the sensitivity of hydrologic response to potential climate change was carried out utilizing HSPF model in the Zarqa River Watershed, Jordan (Abdulla et al. 2009). In the Tarim River Basin, another arid and semi-arid region, the VIC model (Lu et al. 2010) and a monthly water balance model (Peng and Xu 2010) were applied to analyze the potential effects of climate change on streamflow under the GCM A2 and B2 scenarios (Lu et al. 2010). Wu et al. (2012) applied an improved SWAT model to evaluate the impacts of climate change on the water cycle in the semi-arid James River Basin (JRB) in mid-western USA. Mengistu and Sorteberg (2012) applied the SWAT model to test the sensitivity of annual streamflow to climate change within the Eastern Nile River basin and results indicated that the dependence of the response on the strength of the changes was not linear. By using sensitivity-based method and dynamic water balance model, Zuo et al. (2014) identified streamflow response to climate change in the Wei River Basin.

The Luanhe River is the second largest river into the Bohai Sea of north China, and belongs to typical semi-arid and seasonal wind climate region. It is an important natural barrier and water resource for Beijing, Tianjin and Tangshan Region. Since the 1980s, the streamflow of the Luanhe River Basin (LRB) has dramatically decreased. Rapid economic development, population growth and water resources inefficient use in this region have caused serious concerns over the adequacy of the quantity and quality of water withdrawn from the Luanhe River in the future. Moreover, the LRB is a typical fragile eco-environment region of North China, and the hydrological cycle in this basin is very sensitive to climate changes. Therefore, it is urgently needed to evaluate water availability in this basin. In the past, many hydrologists have analyzed hydrological impacts of climate change in this basin. Zhang et al. (2011) applied 
SWAT model to simulate streaflow and analyse impacts of climate change on the hydrological cycle. Using VIC model, Bao et al. (2012) investigated the impact of climate variability and human activities on hydrological cycle and results showed that climate variability was the major driving factor for the streamflow decrease. Liu et al. (2013) studied quantitatively impacts for climate change on runoff in this basin using HBV model. In general, the hydrological processes are very complex in arid and semi-arid basins. In the process of studying the runoff generation mechanism, Li and Feng (2009) found that there was not a single runoff generation mechanism, but both infiltration excess and saturation excess mechanism were involved in LRB. However, HBV model only considers the saturation flow generation mechanism and cannot perform well in semiarid area. VIC model has difficult in simulate surface runoff well in arid and semiaird regions, owing to not simulating the infiltration excess runoff (Xie et al. 2003). And SWAT model uses CN method to determine amounts of infiltration and surface runoff, assuming that the moisture content distribution is similar for each runoff event. This is not the case in many regions (White et al. 2011), especially semiarid ones. In addition, most of these studies regarded the LRB as a whole and didn't divide it into sub-basins to analyze the hydrologic impact of climate change. Due to high spatial variability of watershed characteristics and precipitation, hydrological response to climate change is different for different sub-basin. Therefore, to maintain the sustainable development of regional economics, it is necessary to use a model suitable for semi-arid basins, to investigate the influence of climate change on hydrological processes in each subbasin of LRB.

HIMS (hydroinformatic modeling system) model, proposed by Liu et al. $(2006,2008)$, is a distributed hydrologic model, which uses LCM model (Liu and Wang 1980) to calculate runoff. HIMS model considers both rainfall excess runoff and saturation runoff mechanism, and has been applied widely in semi-arid regions of China. However, there are few applications of HMS model to simulate the impact of climate change on streamflow in the Luanhe River Basin. In this study, we applied HIMS model to simulate the hydrological system and analyze the impact of climate change of eight sub-basins of LRB. The main objectives of this study were to: (i) test the performance of HIMS model for hydrological simulation during 1995-2008 in the LRB, compared with SIMHYD and XAJ models; (ii) investigate the relationships between precipitation, air temperature, and streamflow at different scales in the LRB by applying HIMS model; and (iii) analyze the sensitivity of the annual and monthly streamflow to climate change.

\section{Study Area and Data}

The study area is the LRB, located between $115^{\circ} 30^{\prime}$ and $119^{\circ} 45^{\prime}$ east longitude and $39^{\circ} 10^{\prime}-$ $42^{\circ} 40^{\prime}$ north latitude in northern China. The Luanhe River rises on the Mongolia Plateau, travels through the Yanshan Mountains, and flows directly to Bohai Bay. The catchment area is $44,750 \mathrm{~km}^{2}$ and the main channel length is $888 \mathrm{~km}$ with eight major tributaries (Liuhe, Baohe, Sahe, Laoniuhe, Wuliehe, Xingzhouhe, Yimatuhe, and Yixunhe Rivers) (Fig. 1). The average annual temperature is $5-8{ }^{\circ} \mathrm{C}$, with maximum $43.3{ }^{\circ} \mathrm{C}$ and minimum $-28.4{ }^{\circ} \mathrm{C}$. The average annual evaporation is $1142 \mathrm{~mm}$, and the aridity index is 2.2 . The average annual precipitation is $535 \mathrm{~mm} .70-85 \%$ of the annual precipitation occurs in June-September. The annual variability of precipitation is very great. The maximum annual precipitation is two times the minimum, because of the unstable characteristics of the duration, intensity, and impact region of the subtropical high over the northern pacific in summer. Runoff in the flood season accounts for $60-80 \%$ of the annual total. In this study, eight sub-basins were chosen as the 
study area: the Liuhe, Baohe, Sahe, Laoniuhe, Wuliehe, Xingzhouhe, Yimatuhe, and Yixunhe River sub-basins.

There are 8 meteorological stations and 27 rainfall stations selected in this study area. Daily precipitation, maximum and minimum air temperature were used. And the observed data of 1995-2008 were selected. To avoid the influence of human activity to hydrological processes, natural streamflow of 1995-2008 after reduction were employed for comparison with model results and analyzing hydrological impacts of climate change in LRB. Data from 1995 to 2004 were used for calibration and the last 4 years (2005-2008) are used for validation. The above datasets are all obtained from China Meteorological Data Sharing Service System and Chengde Bureau of Hydrology. Digital elevation model (DEM) with a spatial resolution of

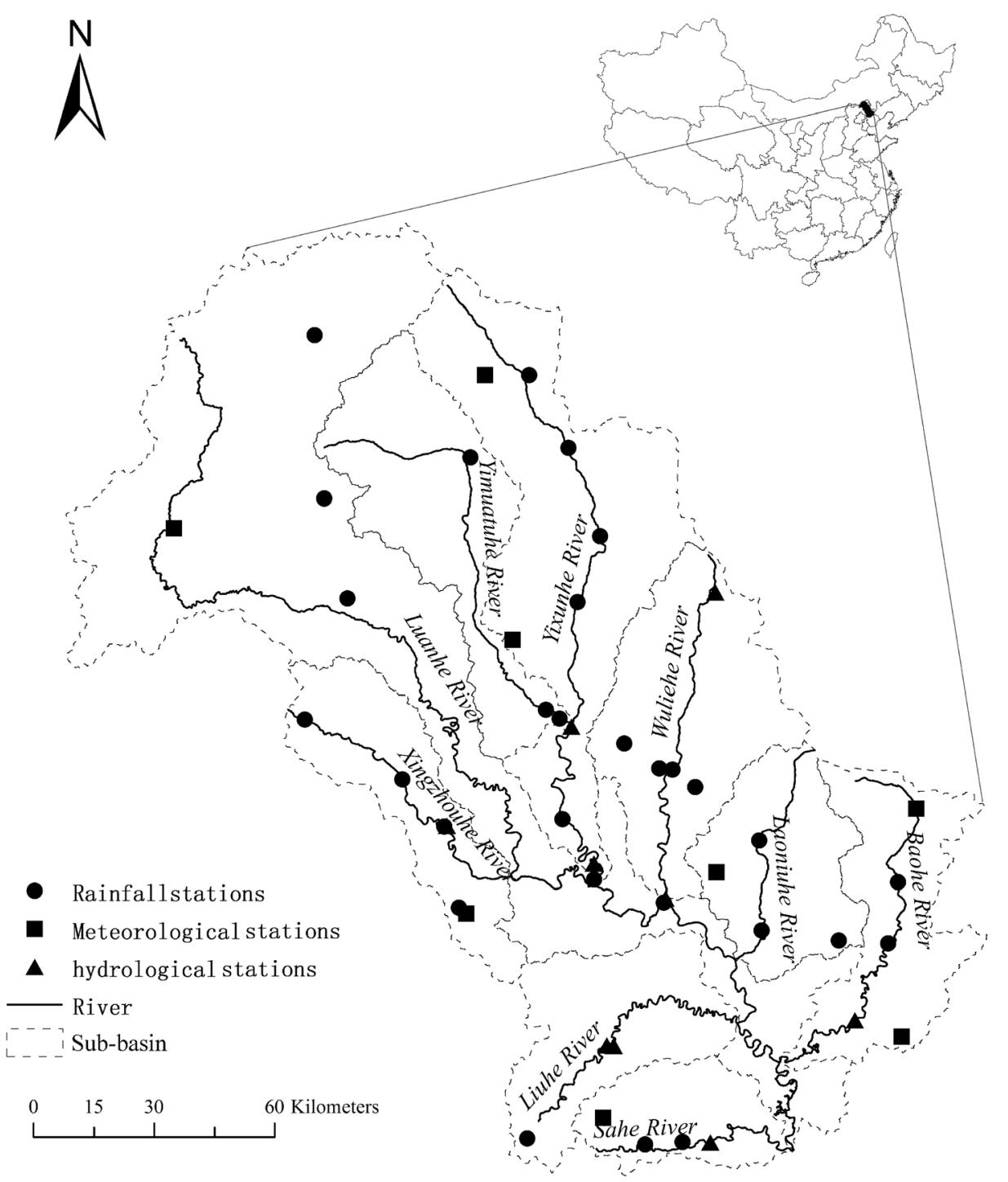

Fig. 1 Map showing the Luan River basin 
$30 \mathrm{~m}$ was downloaded from the International Scientific Data Service Platform, Chinese Academy of Sciences.

\section{Methodology}

\subsection{HIMS Model}

HIMS model, one of the domestic watershed models, can be widely used for predicting the long-term effects of water resources management practices in large watersheds. It can simulate potential evapotranspiration, actual evapotranspiration, infiltration, surface runoff, interflow runoff, groundwater runoff, groundwater recharge, and channel routing. The model has been successfully used in China and Australia (Liu et al. 2008), and has been shown to efficiently simulate streamflow with a simple structure. HIMS model structure is shown in Fig. 2.

HIMS model requires information of weather, hydrology and topography to derive the parameters that control the hydrological processes in a given catchment. DEM was used to divide the watershed into sub-basins, linked throughout the stream network. It contains two stores for soil moisture and groundwater. And the total runoff is separated into three components, surface runoff, interflow and baseflow. There are nine parameters needed to be calibrated. A brief description of calibration parameters used is given in Table 1 (Jiang et al. 2013). Here we briefly describe the calculations for potential evapotranspiration, actual evapotranspiration, infiltration, surface runoff, interflow runoff, groundwater runoff, groundwater recharge and channel routing. For detailed description of the model, refer to Liu et al. (2008).

The potential evapotranspiration $E T_{0}$ and actual evaporation $E T_{a}$ are described as follows:

$$
E T_{0}=a\left(\frac{R A_{\max }}{L}\right)(T+17.8)\left(T_{\max }-T_{\min }\right)^{b},
$$

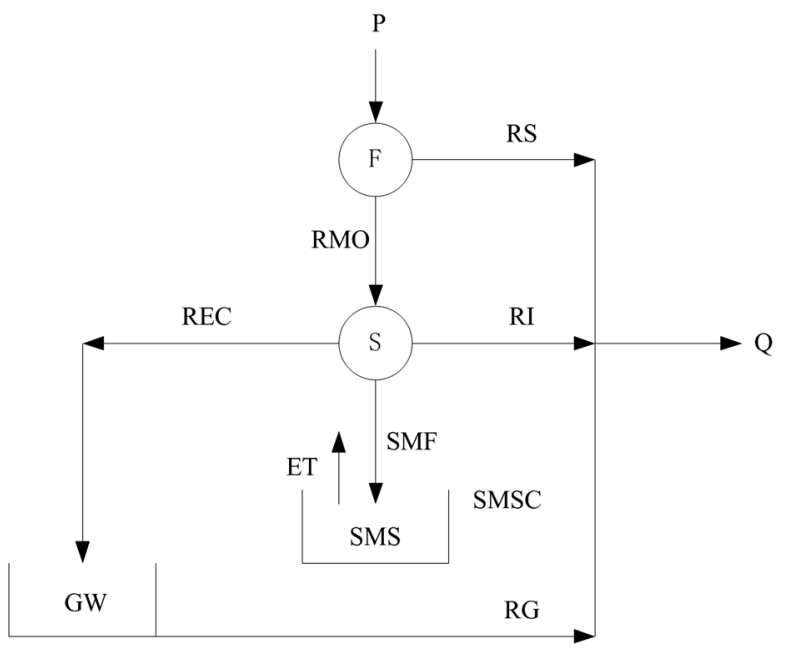

P: Precipitation

ET: Evapotranspiration RMO: Infiltration

REC: Groundwater recharge

SMF: Soil moisture recharge

SMS: Soil moisture storage

SMSC: Soil mositure storage capacity

GW: Groundwater storage

RS: Surface runoff

RI: Interflow

RG: Groundwater runoff

Q: Total basin discharge

Fig. 2 Conceptualization of HIMS model 
Table 1 Description of the parameters and allowable ranges of HIMS model

\begin{tabular}{lll}
\hline Parameter & Description & Allowable range \\
\hline $\mathrm{SMSC}$ & Maximum soil moisture storage capacity of the soil layer (mm) & $50-1000$ \\
$\mathrm{R}$ & Infiltration coefficient & $0.1-2$ \\
$\mathrm{r}$ & Infiltration coefficient & $0.1-1$ \\
$\mathrm{La}$ & Interflow coefficient & $0.1-2$ \\
$\mathrm{Rc}$ & Groundwater recharge coefficient & $0.01-2$ \\
$\mathrm{C}$ & Evapotranspiration coefficient & $0.01-20$ \\
$\mathrm{~Kb}$ & Baseflow coefficient & $0.01-1$ \\
$\mathrm{C} 1$ & Muskingum coefficient & $0.01-1$ \\
$\mathrm{C} 2$ & Muskingum coefficient & $0.01-1$ \\
\hline
\end{tabular}

$$
E T_{a, t}=E T_{0, t} \cdot\left(1-\left(1-\frac{S M S_{t}}{S M S C}\right)^{\varepsilon}\right)
$$

The rainfall infiltration and surface runoff can be described as follows:

$$
\begin{gathered}
f_{t}=R \cdot P_{t}{ }^{r}, \\
R S_{t}=P_{t}-f_{t}=P_{t}-R \cdot P_{t}^{r},
\end{gathered}
$$

The interflow $R I$, groundwater recharge $R E C$, baseflow $R G$ and total runoff $T R$ are determined by:

$$
\begin{gathered}
R I_{t}=L_{a} \cdot\left(S M S_{t} / S M S C\right) \cdot f_{t}, \\
R E C_{t}=R_{c} \cdot\left(S M S_{t} / S M S C\right) \cdot\left(f_{t}-R I_{t}\right), \\
R G_{t}=K_{b} \cdot\left(G W_{t}+R E C_{t}\right), \\
T R_{t}=R S_{t}+R I_{t}+R G_{t},
\end{gathered}
$$

where, $a$ and $b$ are empirical parameters. $R A_{\max }$ is maximum radiation. $T, T_{\max }$ and $T_{\min }$ are daily average, maximum and minimum temperature respectively. $E$ is the evapotranspiration coefficient. $L, f_{t}, P_{t}, R S_{t}, L_{a}, R_{c}, K_{b}, S M S C, S M S$ and $G W$ are latent heat of vaporization, infiltration, precipitation, surface runoff, efficiencies for interflow, groundwater recharge, baseflow respectively, the maximum value of soil moisture storage capacity, unsaturated soil moisture storage and groundwater storage. $\mathcal{E}, R, r, L_{a}, R_{c}, K_{b}$ and $S M S C$ are parameters, need to be calibrated.

Finally, the Muskingum method (Franchini and Lamberti 1994) is examined for flow concentration of river channels. $C_{1}$ and $C_{2}$ are two routing parameters, need to be calibrated. 


\subsection{SIMHD Model}

SIMHYD is a lumped conceptual rainfall- runoff model. It can simulate surface runoff, interflow, and baseflow using precipitation and potential evapotranspiration as input data (Chiew et al. 2002). This model has been one of the most commonly used rainfall-runoff models and been extensively tested in Australia (Chiew 2006; Zhang and Chiew 2009; Zhan et al. 2014).

\subsection{XAJ Model}

The XAJ (Xinanjiang) model developed in 1973 by Prof. Zhao (1992 and 1995) is by far the most important conceptual rainfall-runoff model in China. It can estimate actual evapotranspiration, soil moisture storage, surface runoff, interflow, and groundwater runoff and has been successfully used for flood forecasting (Bao et al. 2011; Li et al. 2009; Jiang et al. 2014).

\subsection{Methods of Model Calibration and Validation}

How well of parameters selection affects the successful application of a hydrological model (Shin et al. 2013). Theoretically, they can be assigned values from actual data, but this is almost impossible because of temporal and spatial variations in complicated hydrological processes. Instead, an inverse problem is solved using automatic optimization techniques. The parameters are optimized by fitting the simulation as closely as possible to the observation. To obtain successful calibration using automatic optimization routines, it is necessary to formulate the calibration objective. For comprehensive considering of water error and fit between observed and simulated streamflow, in this study model parameters were optimized by minimizing values of the objective function given by

$$
f(x)=\frac{1}{N} \sum_{i=1}^{N}\left(Q_{o b s, i}-Q_{s i m, i}\right)^{2}\left(1+\frac{\left|\bar{Q}_{o b s}-\bar{Q}_{s i m}\right|}{\bar{Q}_{o b s}}\right),
$$

where $x$ are parameters to be calibrated, $Q_{o b s, i}$ and $Q_{s i m, i}$ are observed and simulated streamflow, $\bar{Q}_{o b s}$ and $\bar{Q}_{\text {sim }}$ are the average values of the observed and simulated streamflow, and $N$ is the length of the time series.

Traditional optimization methods to calibrate hydrological models include genetic algorithms (Dumedah et al. 2010; Kaini et al. 2012; Wang 1991, 1997), shuffled complex evolution method (Chu et al. 2010; Duan et al. 1992, 1994; Guo et al. 2013; Joseph and Guillaume 2013; Vrugt et al. 2003a, b), and particle swarm optimization (PSO) (Gill et al. 2006; Jiang et al. 2010, 2013; Shi et al. 2013; Zhang et al. 2009). Recent research has shown that the PSO approach has many computational advantages over traditional evolutionary computing (Chau 2007). However, the drawback of premature convergence degrades its performance and reduces its global search ability. Jiang et al. (2013) proposed a multi-swarms shuffling evolution algorithm based on selfadaptive particle swarm optimization (MSSE-SPSO), which referred to the ideas of population division and biological evolution to keep the diversity of the population and avoid premature convergence. Compared with PSO and MSSE-PSO for model calibration, MSSE-SPSO was found to remarkably improve the simulation accuracy during calibration and verification period. In this paper, we applied MSSE-SPSO to calibrate HIMS model parameters. The calibration was performed by sampling particles from parameters space to find the optimal parameter set that minimizes the objective function. To avoid the effects of using random values, we ran the calibration several times and took the average of the solutions as the optimal parameter set. 


\subsection{Model Performance Assessment}

Nash-Sutcliffe efficiency criterion (Nash and Sutcliffe, 1970) and relative cumulative error between the observed and simulated series were used to evaluate the performance of the model. They are defined as

$$
\begin{gathered}
N S E=1-\frac{\sum_{i=1}^{N}\left(Q_{o b s, i}-Q_{s i m, i}\right)^{2}}{\sum_{i=1}^{N}\left(Q_{o b s, i}-\bar{Q}_{o b s}\right)^{2}}, \\
R E=\frac{\left|\bar{Q}_{o b s}-\bar{Q}_{\text {sim }}\right|}{\bar{Q}_{o b s}} \times 100 \%,
\end{gathered}
$$

We expect the value of NSE to approach unity when we have a good simulation of observed streamflow series. And the value of RE is expected to be close to zero when we have a good simulation of the total volume of the observed streamflow series.

\subsection{Sensitivity of Streamflow to Climatic Changes}

Up to now, two approaches have been developed to calculate climate change scenarios. The first approach is based on general circulation models (GCMs) (Samadi et al. 2013). The second is based on an incremental scenario dependent on probable changes in regional climate. GCMs are used to generate climate change projections at a large spatial and temporal scale. Because of the coarse resolution of GCMs and the simplification of the hydrologic cycle in climate models, it is not possible to make reliable predictions of regional hydrologic changes directly from climate models (Arora 2001; Jiang et al. 2007). Even as GCMs grid sizes tend towards one or two degrees, they are still significantly mismatch with the scale of many hydrological models (Varis et al. 2004; Xu et al. 2005). Given the deficiencies of GCMs predictions, hypothesized scenarios have been widely used as input to hydrological models (Füssel and Klein 2006; Vicuna and Dracup 2007; Xu 2000). This is a simple and direct approach to set climate change scenarios. Guo et al. (2002) proposed a macro-scale and semi-distributed monthly water balance model to investigate the sensitivity of hydrological and water resource systems variables to global warming under different scenarios, for the Ganjiang and Hanjiang basins in the Yangtze River. Those scenarios involved combining temperature increases or decreases of 1,2 , and $3{ }^{\circ} \mathrm{C}$ with precipitation changes of $-100,-50,-25,0,25,50$, and $100 \%$. The Sacramento soil moisture accounting model combined with the Anderson Snow model was applied to study climate change impacts in California (Miller et al. 2003). That study used hypothesized climate scenarios of incrementally uniform temperature shifts $\left(1.5,3.0\right.$, and $\left.5^{\circ} \mathrm{C}\right)$ for decreasing, unchanged, and increasing precipitation ratios $(0.70,0.82,0.91,1.00,1.09$, 1.18, and 1.30). Jiang et al. (2007) used six-monthly water balance models to simulate the impact of climate change on hydrological processes, based on 15 perturbed climate scenarios in the Dongjiang catchment, a tributary of the Pearl River (Zhujiang) located in southern China.

In this study, according to climate change trends of the LRB, hypothetical scenarios for future climate change were set with temperature changes of $0,1,2$, and $3{ }^{\circ} \mathrm{C}$, and precipitation changes of $0, \pm 10$, and $\pm 20 \%$, to analyze the impact of precipitation and temperature changes 
on streamflow. The temperature and precipitation perturbation were applied by adding the prescribed change to the baseline climate (Van Griensven et al. 2002). Thus, we derived 20 hypothetical climate change scenarios from combinations of four temperature increases and five precipitation changes.

\section{Results}

\subsection{Comparison of Three Rainfall-Runoff Models (Model performance)}

The streamflow simulation results of HIMS, SIMHYD, and XAJ models for the Liuhe, Baohe, Sahe, Laoniuhe, Wuliehe, Xingzhouhe, Yimatuhe, and Yixunhe Rivers sub-basins are listed in Table 2. Overall, the streamflow predictions by HIMS model were better than by SIMHYD and XAJ models. Simulations of streamflow in the Liuhe, Baohe, Sahe, Laoniuhe, and Wuliehe Rivers' sub-basins were successful, with NSE values of 0.78-0.97 and RE values of -15.56 to $16.97 \%$.

Observed and simulated yearly streamflow hydrographs from HIMS, SIMHYD, and XAJ models from 1995 to 2008 in the eight rivers (the eight sub-basins) are shown in Fig. 3. It can be seen that all three models produce good simulations of the yearly streamflow in the Liuhe, Baohe, and Sahe Rivers' sub-basins. However, there were larger differences between models for the Laoniuhe, Wuliehe, Xingzhouhe, Yimatuhe, and Yixunhe Rivers' sub-basins.

The observed and simulated mean monthly streamflow calculated by HIMS, SIMHYD, and XAJ models for 1995-2008 are shown in Fig. 4. All three models produce good simulations of mean monthly runoff in the Liuhe, Baohe, Sahe, Laoniuhe, Wuliehe, and Xingzhouhe Rivers' sub-basins, except that XAJ model simulates small values for the winter and spring months in

Table 2 Simulation results at different hydrological stations

\begin{tabular}{|c|c|c|c|c|c|c|c|}
\hline & \multirow[t]{2}{*}{ Sub-basins } & \multicolumn{2}{|c|}{ XAJ model } & \multicolumn{2}{|c|}{ SIMHYD model } & \multicolumn{2}{|c|}{ HIMS model } \\
\hline & & NSE & $\mathrm{RE}(\%)$ & NSE & $\mathrm{RE}(\%)$ & NSE & $\mathrm{RE}(\%)$ \\
\hline \multirow[t]{8}{*}{ Calibration (1995-2004) } & Liuhe River & 0.82 & 22.51 & 0.90 & 12.67 & 0.90 & 7.61 \\
\hline & Baohe River & 0.94 & 39.66 & 0.93 & 35.01 & 0.96 & -13.98 \\
\hline & Sahe River & 0.96 & -15.60 & 0.97 & -4.46 & 0.97 & 16.97 \\
\hline & Laoniuhe River & 0.88 & 24.68 & 0.74 & 40.11 & 0.89 & 1.98 \\
\hline & Wuliehe River & 0.75 & 7.71 & 0.78 & 12.67 & 0.84 & -15.56 \\
\hline & Xingzhouhe River & 0.81 & 20.43 & 0.78 & 23.27 & 0.82 & 19.25 \\
\hline & Yimatuhe River & 0.42 & 7.98 & 0.46 & 32.49 & 0.60 & 8.03 \\
\hline & Yixunhe River & 0.70 & 10.19 & 0.54 & 44.11 & 0.82 & -1.51 \\
\hline \multirow[t]{8}{*}{ Verification (2005-2008) } & Liuhe River & 0.82 & 10.18 & 0.77 & 26.44 & 0.84 & 11.43 \\
\hline & Baohe River & 0.79 & 57.91 & 0.81 & 57.69 & 0.88 & -11.80 \\
\hline & Sahe River & 0.94 & 23.64 & 0.95 & 18.18 & 0.96 & 1.04 \\
\hline & Laoniuhe River & 0.82 & 60.59 & 0.81 & 40.37 & 0.88 & -2.27 \\
\hline & Wuliehe River & 0.74 & 3.61 & 0.71 & 7.91 & 0.78 & 3.52 \\
\hline & Xingzhouhe River & 0.13 & -2.25 & 0.25 & 11.01 & 0.26 & 4.03 \\
\hline & Yimatuhe River & 0.31 & -5.55 & 0.13 & 52.02 & 0.30 & 6.34 \\
\hline & Yixunhe River & 0.78 & 9.11 & 0.78 & 28.05 & 0.87 & 4.04 \\
\hline
\end{tabular}



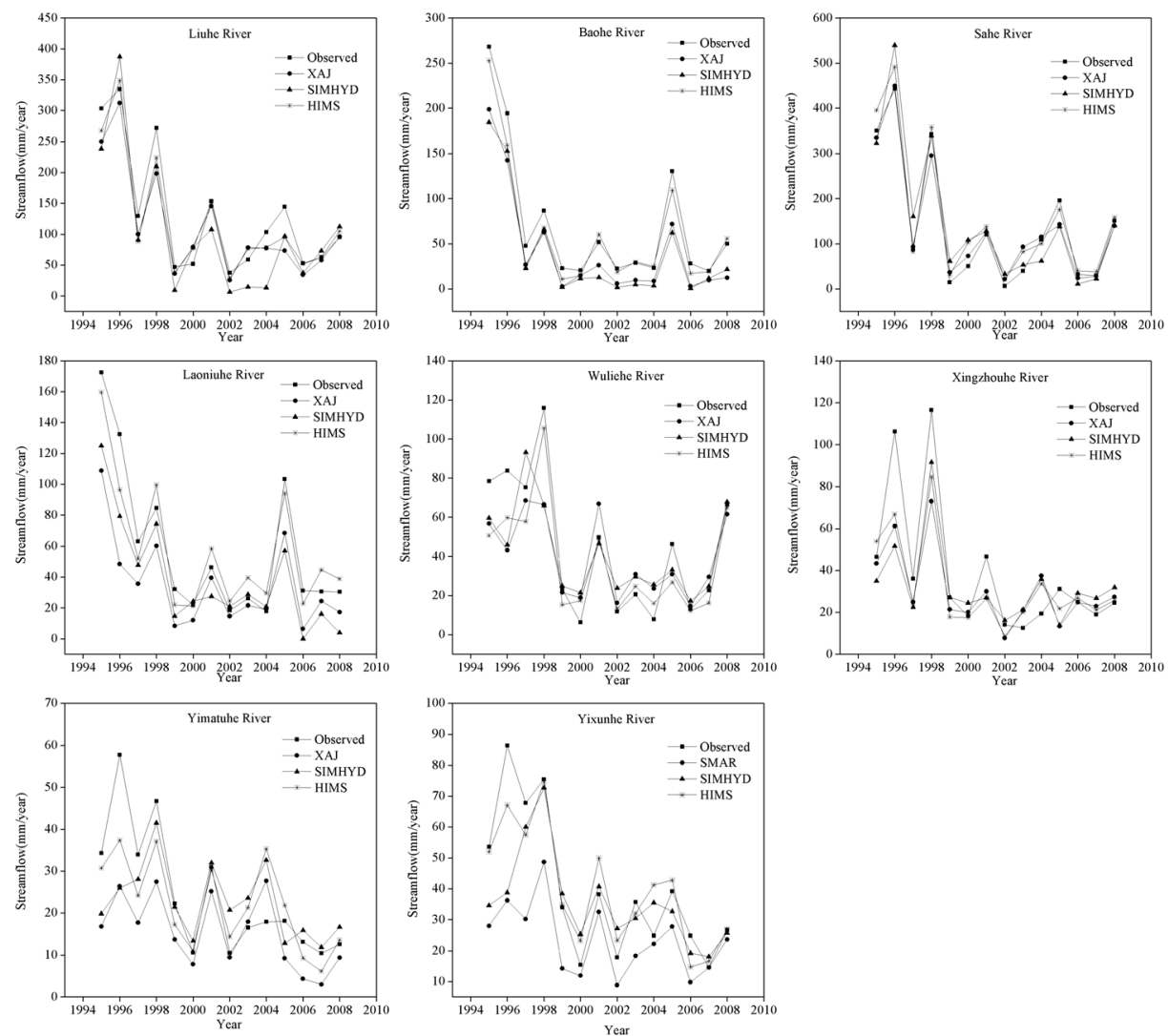

Fig. 3 Comparison of the yearly streamflow for 1995-2008 calculated using the three models

the Yixunhe River sub-basin and none of the models are accurate for the Yimatuhe River subbasin in March and April.

To compare the models' capabilities at simulating dynamics of monthly streamflow series, we analyzed the different monthly streamflow values and compared them with the observed values using a linear regression equation. The scatter plot and regression results are shown in Fig. 5. The results show that: (1) all models correlated well with the observed values, with $\mathrm{R}^{2}$ values of 0.90 in the Liuhe, Baohe, and Sahe River sub-basins, but HIMS model had the largest $\mathrm{R}^{2}$ values for the other sub-basins; (2) the regression slope of HIMS model had the smallest bias.

Generally, these results demonstrate that HIMS model is more accurate than the XAJ and SIMHYD models.

\subsection{Differences Between Sub-basins when Predicting Hydrological Responses to Changed Climate}

It is important to analyze the effects of climate change on hydrological variables. Obviously, streamflow is essential for providing an indication of the extent of the impacts of climatic change on water resource (Jiang et al. 2007). The impacts of the perturbed temperature and precipitation scenarios on annual and mean monthly streamflow are shown in Figs. 6, 7, 8 and 9 , and details are given in the sections below. We investigated climate sensitivity scenarios by 

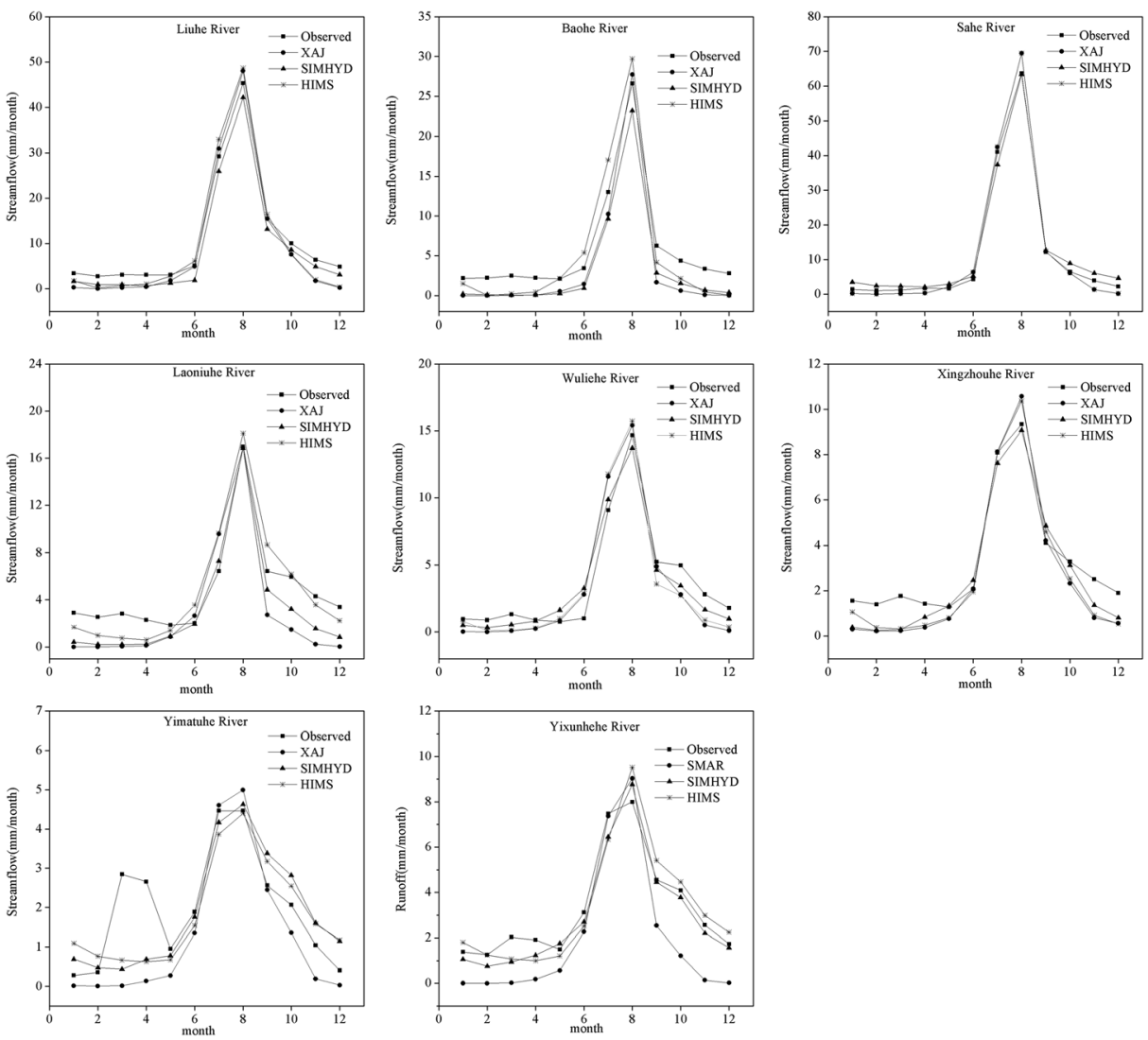

Fig. 4 Comparison of the mean monthly streamflow for 1995-2008 calculated using the three models

perturbing the baseline simulation that is the input to HIMS model for simulating the streamflow under different climate scenarios.

\subsubsection{Mean Annual Changes}

The percent changes to mean annual streamflow with response to the 20 climate change scenarios used to drive HIMS model are shown in Figs. 6 and 7. The streamflow changes in response to temperature changes for a given precipitation change are shown in Fig. 6. The eight lines in each branch represent the results for the eight sub-basins and the slope of each line represents the changing streamflow rate with temperature change (Jiang et al. 2007). The differences between the eight branches represent the influences of different precipitation changing scenarios on streamflow. The results show that:

(1) Streamflow is positively related to precipitation and negatively relationship obtained from the streamflow related to temperature in all eight sub-basins. The annual streamflow increases with increasing precipitation, and decreases with increasing temperature for all eight sub-basins. 

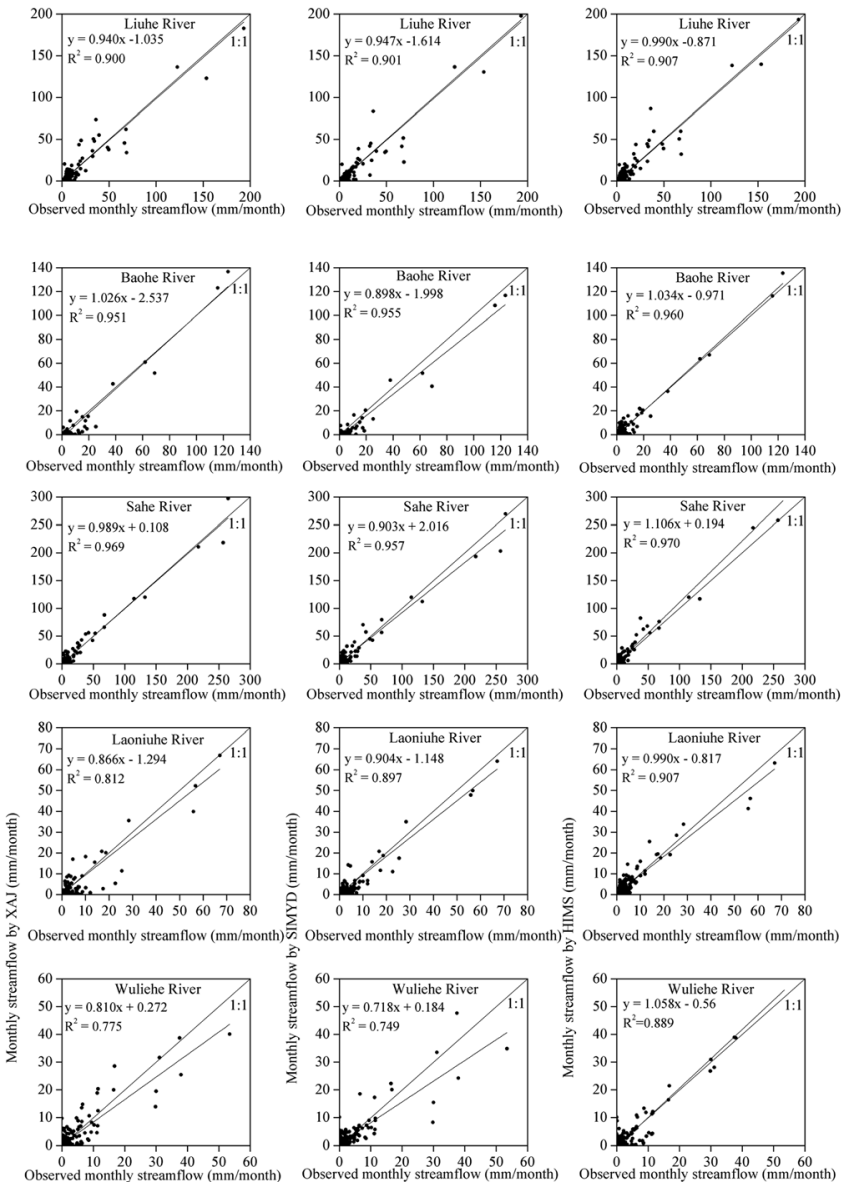

Observed monthly streamflow (mm/month)
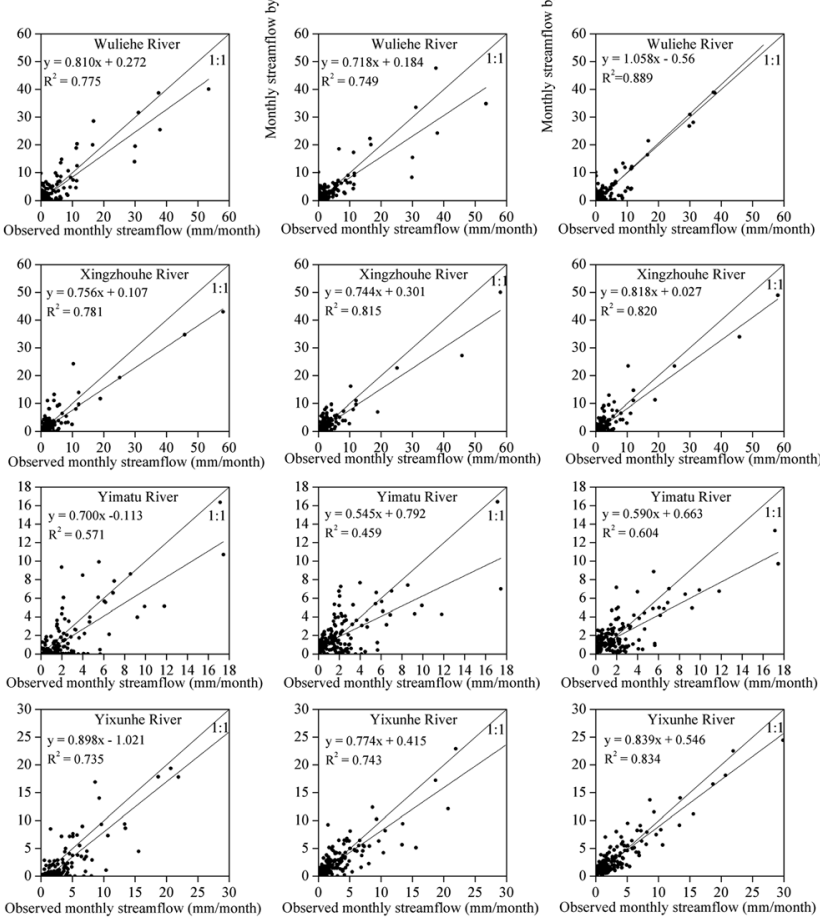

Fig. 5 Scatter plots and regression equations comparing the monthly simulated streamflow with the observed streamflow, for 1995-2008 


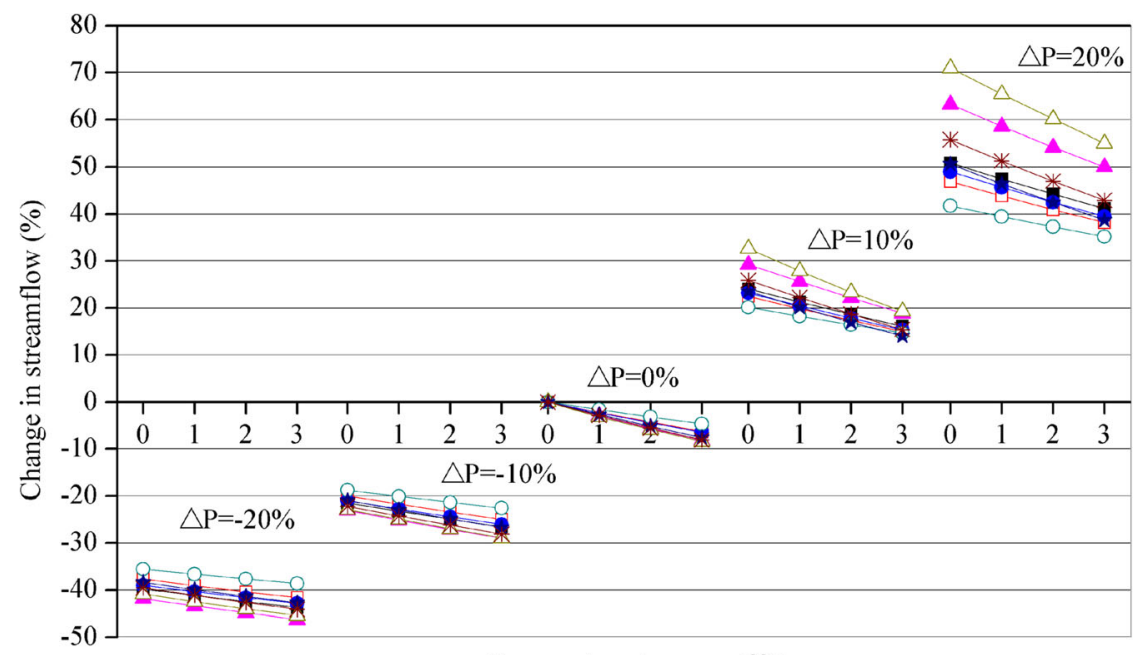

Temperature increase $\left({ }^{\circ} \mathrm{C}\right)$

- LNHR $\square$ LHR $\bullet$ BHR $\bigcirc$ SHR $\triangle$ WLHR $\triangle$ XZHR $\star$ YMTHR $*$ YXHR

Fig. 6 Comparison of mean annual changes in streamflow in response to temperature changes for a given precipitation change, for eight sub-basins

(2) When precipitation does not change, one-, two-, and three-degree increases in the air temperature result in a reductions in annual streamflow of approximately 1.61-3.16, $3.17-5.82$, and $4.65-8.39 \%$, respectively, in all eight sub-basins. When the precipitation decreases by $20 \%$, zero-, one-, two-, and three-degree increases in the air temperature result in reductions in annual streamflow of approximately $35.56-41.87,36.64-43.39$,

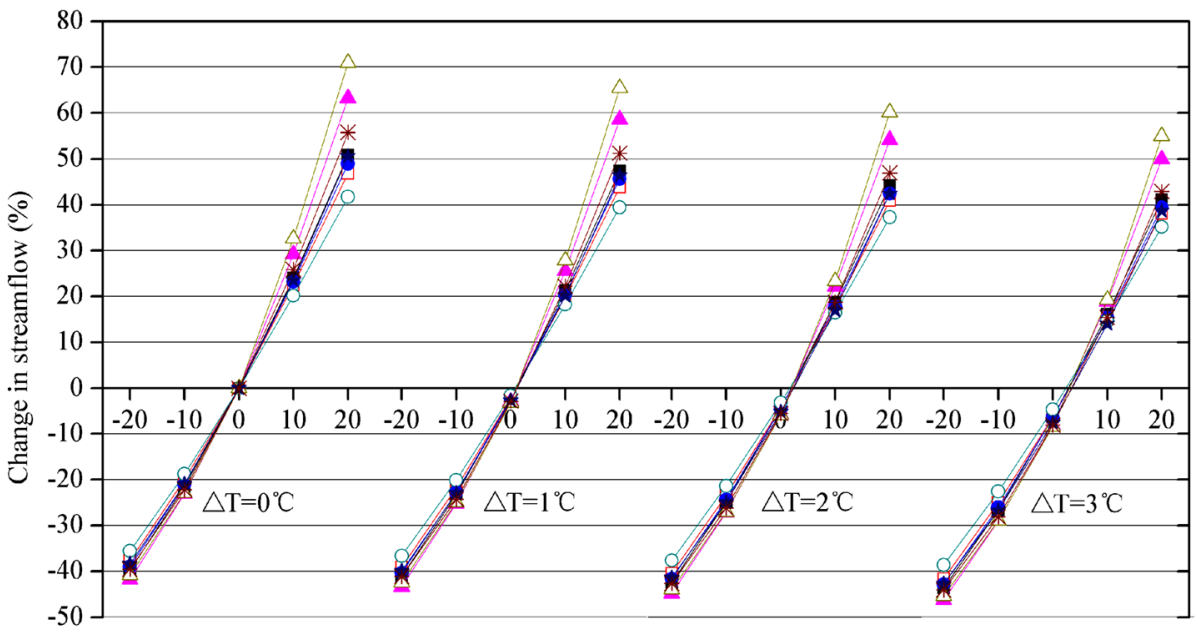

Change in precipitation (\%)

- LNHR $\square$ LHR - BHR - SHR $\triangle$ WLHR $\triangle$ XZHR $\star$ YMTHR $*$ YXHR

Fig. 7 Comparison of mean annual changes in streamflow in response to precipitation changes for a given temperature change, for eight sub-basins 


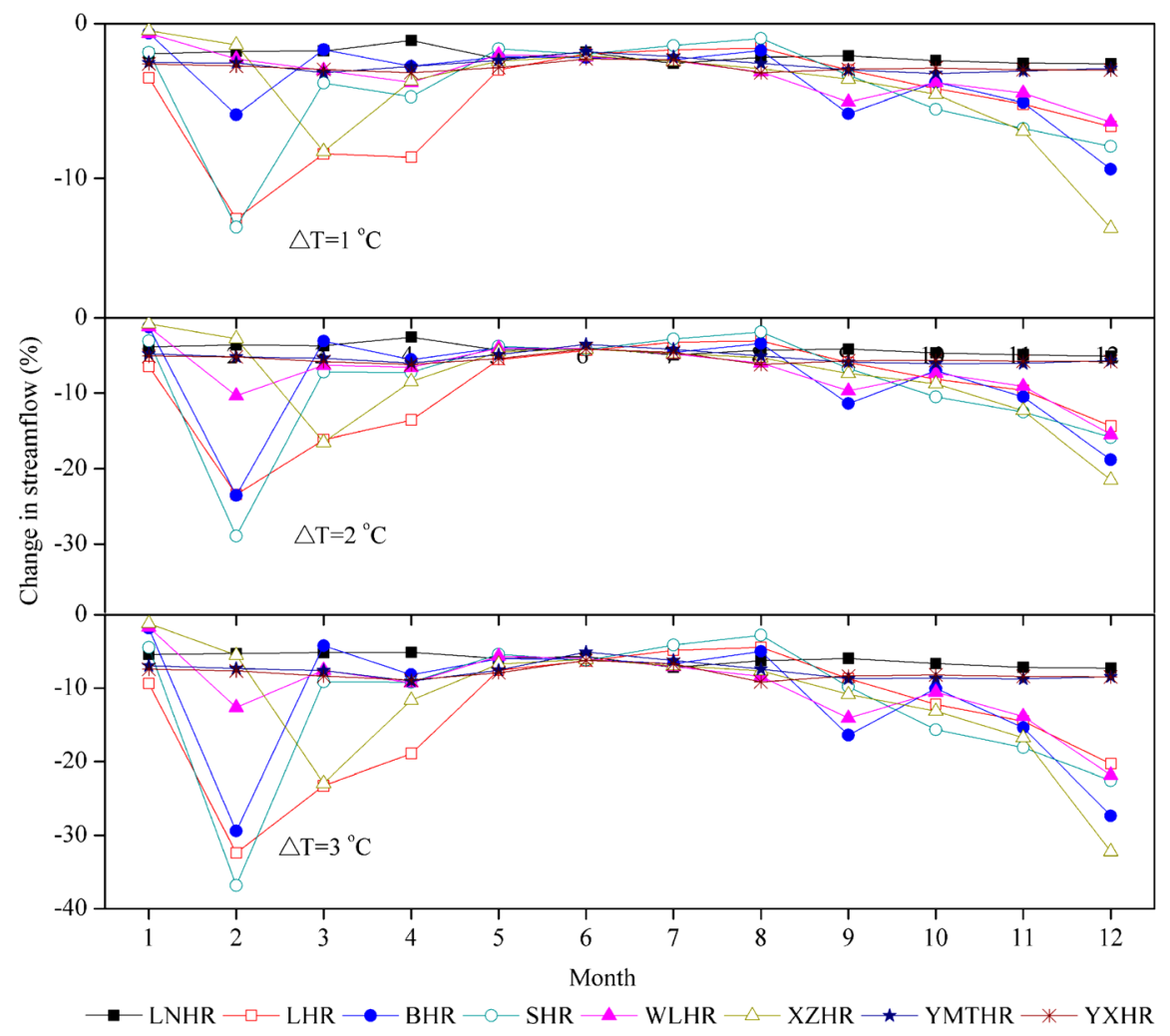

Fig. 8 Comparison of mean monthly streamflow changes in response to temperature changes for a precipitation unchanged, for eight sub-basins

37.64-44.86, and 38.62-46.25\%, respectively, for different sub-basins. When the precipitation increases by $20 \%$, annual streamflow increases by approximately 41.78 $70.98,39.46-65.47,37.30-60.17$, and $35.20-55.01 \%$ for temperature respective increases of zero, one, two, and three degrees.

(3) For all eight sub-basins, the streamflow response to precipitation change is more sensitive when the trend is increasing than if it is decreasing.

The streamflow changes in response to precipitation changes for given temperature changes are shown in Fig. 7. When there is no change in temperature, changes of $-20,-10,10$, and $20 \%$ in precipitation result in a change in annual streamflow of approximately -41.87 to $-35.56,-23.06$ to $-18.74,20.17-32.68$, and $41.73-70.98 \%$, respectively. When there is a temperature increase of $1{ }^{\circ} \mathrm{C}$, changes of $-20,-10,10$, and $20 \%$ in precipitation result in changes in annual streamflow of approximately -43.39 to $-36.63,-25.14$ to $-20.09,18.23-27.87$, and $39.47-65.47 \%$, respectively. When there is a temperature increase of $3{ }^{\circ} \mathrm{C}$, changes of $-20,-10,10$, and $20 \%$ in precipitation result in changes in annual streamflow of approximately -46.25 to $-38.62,-28.96$ to -22.57 , 14.00-19.28, and 35.20-55.01\%, respectively.

Streamflow changes are more sensitive to precipitation changes than to temperature for all eight sub-basins, according to the slope of each line in Figs. 6 and 7. 


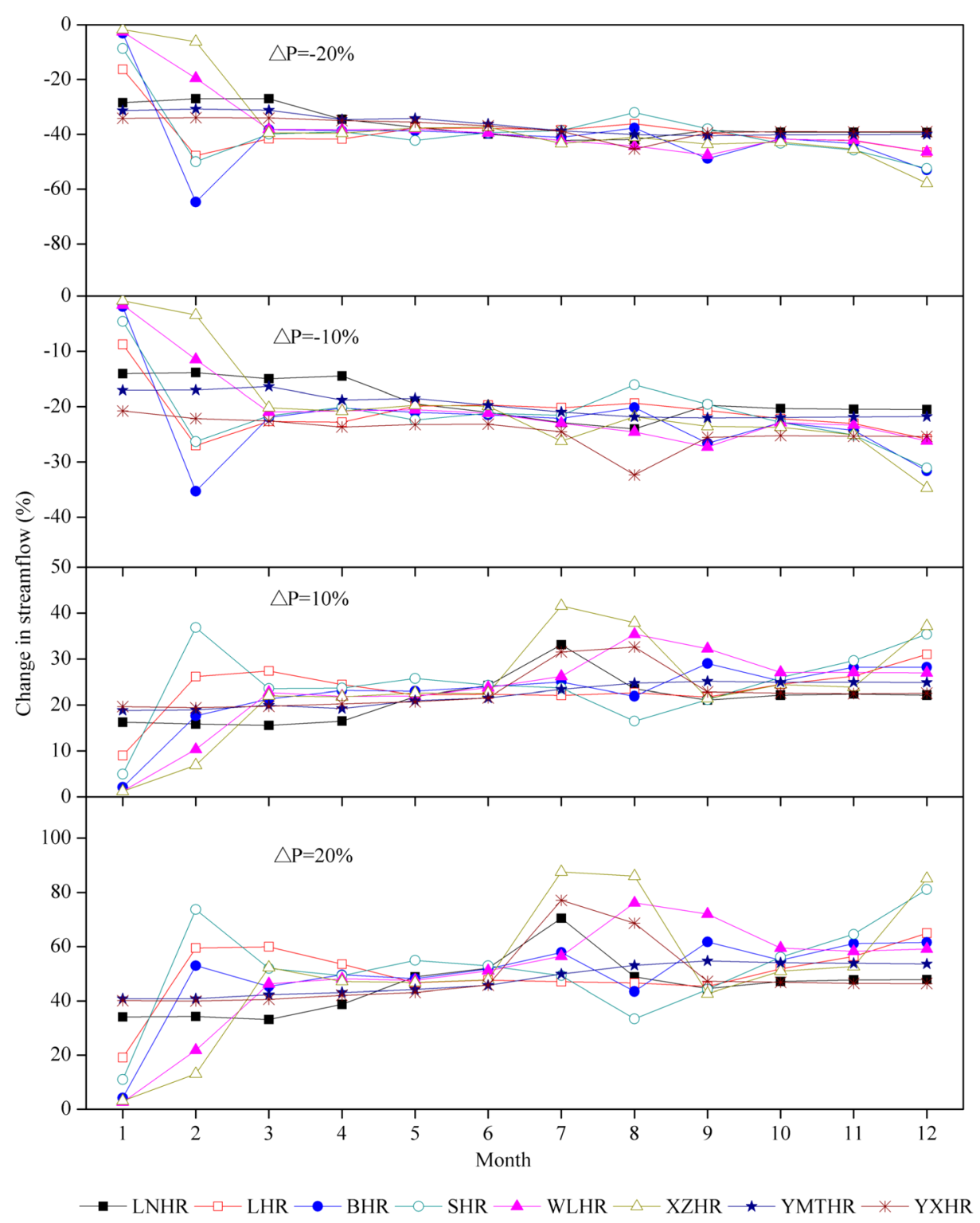

Fig. 9 Comparison of mean monthly streamflow changes in response to precipitation changes for a temperature unchanged, for eight sub-basins

\subsubsection{Mean Month Changes}

To evaluate seasonal and inter-annual changes, we compared the mean monthly streamflow simulated by HIMS model for the eight sub-basins using various climate change scenarios. The simulated mean monthly streamflow changes in response to temperature changes when precipitation is unchanged are plotted in Fig. 8, and in response to precipitation changes when temperature is unchanged are plotted in Fig. 9. 
Figure 8 shows that:

(1) on average, when precipitation does not change, the mean monthly streamflow changes by -13.22 to $-0.46,-28.95$ to -0.79 , and -36.84 to $-1.19 \%$ for temperature changes of 1,2 , and $3{ }^{\circ} \mathrm{C}$;

(2) when temperature changes, there are larger differences in streamflow change over the winter months.

Figure 9 shows that:

(1) on average, when the temperature does not change, the mean monthly streamflow changes by -35.29 to $-0.86,-64.71$ to $-1.79,1.22-41.58$, and $2.62-87.59 \%$ respectively for precipitation changes of $-20,-10,10$, and $20 \%$;

(2) when precipitation decreases or is unchanged, there are larger differences in streamflow change over the winter months, but when precipitation increases, the larger differences happen in winter and summer months.

\section{Discussion}

\subsection{Sensitivity of Streamflow to Temperature}

The relative sensitivity of the streamflow to changes in temperature (when the precipitation fixed) was analyzed in all eight sub-basins (Fig. 6). Annual streamflow in all sub-basins were sensitive to an increase in temperature and that the sensitivity was changing approximately linearly with temperature. And annual streamflow differences were obvious under different temperature change scenarios, for all eight rivers. When precipitation remained unchanged, the analysis of the streamflow responses to various temperature scenarios indicated that a $1{ }^{\circ} \mathrm{C}$ increase in temperature would produce a $2.26,2.20,2.27,1.61,2.93,3.16,2.65$, and $2.84 \%$ reduction in streamflow for the Laoniuhe, Liuhe, Baohe, Sahe, Wuliehe, Xingzhoueh, Yimatuhe, and Yixunhe River sub-basins, respectively. Therefore, the relationship between streamflow and temperature was more sensitive in the Xingzhouhe River sub-basin, followed by the Wuliehe River sub-basin, and the streamflow sensitivity to temperature in Sahe River sub-basin ranked last.

For a given precipitation, mean monthly streamflow decreased with increasing temperature for all eight sub-basins. There were large differences between different sub-basins (see Fig. 8). The temperature influenced streamflow differently in different months, because of its double effect on snowmelt time and evaporation. The response of mean monthly streamflow to temperature change was similar in the Laoniuhe, Yimatuhe, and Yixunhe Rivers, while the other rivers had a similar pattern of seasonal variation. With increasing temperature, the largest differences happened in the winter and summer, and may be caused by an earlier snowmelt in winter and increasing evaporation losses in summer.

\subsection{Sensitivity of Streamflow to Precipitation}

The sensitivity of annual streamflow to changes in precipitation (when temperatures were fixed) was different among the eight sub-basins (Fig. 7). Annual streamflow differences were also obvious under different precipitation change scenarios for all eight rivers. The magnitudes 
of the streamflow responses to changes in precipitation varied among the different sub-basins, and the differences increased as the precipitation changes increased. When the temperature was unchanged, the analysis of the streamflow responses for the various scenarios indicated that a $10 \%$ increase in precipitation would produce $24.03,22.44,23.17,20.17,29.26,32.68$, 23.54, and $25.89 \%$ increases in streamflow for the Laoniuhe, Liuhe, Baohe, Sahe, Wuliehe, Xingzhouhe, Yimatuhe, and Yixunhe River sub-basins, respectively (Fig. 7). Therefore, the relationship between streamflow and precipitation was more sensitive in the Xingzhouhe River sub-basin, followed by the Wuliehe River sub-basin, and streamflow in the Sahe River subbasin was least sensitive. The changes in sensitivity were different because of differences in topography and catchment characteristics. The land use and soil types of these sub-basins are also quite different.

For a given temperature, the mean monthly streamflow increased with increasing precipitation for all eight sub-basins. There were large differences of mean monthly streamflow between the different sub-basins (see Fig. 9). The change of streamflow for each month was almost consistent in the Laoniuhe, Yimatuhe, and Yixunhe Rivers, while the other rivers had similar patterns of seasonal variations. When $\Delta \mathrm{P} \%<0$, the large differences in the percent changes in streamflow for winter months may be caused by smaller absolute values in streamflow. When $\Delta \mathrm{P} \%>0$, the large differences in the percent changes in streamflow over the winter and summer may be caused by smaller absolute values in streamflow in winter and larger precipitation values in summer.

\section{Conclusions}

We used HIMS rainfall-runoff model to simulate the streamflow in the Luanhe River Basin, and compared our results with SIMHYD and XAJ models. The hypothesized climate scenarios were given by a percentage change in precipitation that was added to the baseline simulation temperatures. We used different climate scenarios as inputs to HIMS model to analyze the impact of climate change on streamflow. Our conclusions can be summarized as follows:

1. Our comparative study of SIMHYD, XAJ, and HIMS models in the Luanhe River catchment from 1995 to 2008 demonstrated that HIMS model's predictions were best. Simulations of monthly streamflow in the Liuhe, Baohe, Sahe, Laoniuhe, Wuliehe, and Yixunhe Rivers' sub-basins were successful, and had NSE values of $0.78-0.97$ and RE values of -15.56 to $16.97 \%$.

2. Different scenarios for precipitation and temperature were used as inputs to HIMS model to simulate annual and monthly streamflow in the eight sub-basins. Annual streamflow was positively related to precipitation, and there was a negative relationship between streamflow and temperature. For all sub-basins, the annual streamflow response to precipitation change was more sensitive when increasing than decreasing, and the sensitivity changed linearly with temperature. The annual streamflow response to climate change was most sensitive in the Xingzhouhe River sub-basin, followed by the Wuliehe River sub-basin, and least sensitive in the Sahe River sub-basin.

3. There were few differences in the inner-streamflow response to climate change in the Laoniuhe, Yimatuhe, and Yixunhe Rivers. For the other rivers, when the temperature changed, there were larger differences in percent changes in streamflow during the winter and summer. When precipitation decreased or was unchanged, the larger differences in streamflow happened during winter. However, when precipitation increased, the larger differences happened during winter and summer. 
Acknowledgments We are grateful to Prof. Hongrui Wang for his helpful suggestions and to Dr. Yaomin Qin for his help in mapping. Funding was supported by the National Natural Science Foundation of China (Nos. 50809004, 51279006), the Key Project of the National Natural Science Foundation of China (No. 41330529) and the National Major Science and Technology Projects for Water Pollution Control and Management (Nos.2012ZX07203-002, 2012ZX07203-003). The HIMS model was programmed and provided for their studies by Prof. Changming Liu, Zhonggen Wang and Hongxing zheng (Institute of Geographic Sciences and Natural Resources Research, Chinese Academy of Sciences, China).

\section{References}

Abdulla F, Eshtawi T, Assaf H (2009) Assessment of the impact of potential climate change on the water balance of a semi-arid watershed. Water Resour Manag 23(10):2051-2068

Arora VK (2001) Streamflow simulations for continental-scale river basins in a global atmospheric general circulation model. Adv Water Resour 24:775-791

Bao H, Zhao L, He Y, Li Z, Wetterhall F, Cloke H, Pappenberger F, Manful D (2011) Coupling ensemble weather predictions based on TIGGE database with Grid-Xinanjiang model for flood forecast. Adv Geosci 29:61-67

Bao ZX, Zhang JY, Wang GQ, Fu GB, He RM, Yan XL, Jin JL, Liu YL, Zhang AJ (2012) Attribution for decreasing streamflow of the Haihe River basin, northern China: climate variability or human activities? J Hydrol 460-46:117-129

Bates B, Kundzewicz ZW, Wu S, Palutikof J (2008) Climate change and water. Intergovernmental Panel on Climate Change (IPCC)

Chau KW (2007) A split-step particle swarm optimization algorithm in river stage forecasting. J Hydrol 346:131-135

Chiew FHS (2006) Estimation of rainfall elasticity of streamflow in Australia. Hydrol Sci J 51:613-625

Chiew FHS, Peel MC, Western AW, Singh VP, Frevert D (2002) Application and testing of the simple rainfallrunoff model SIMHYD. Mathematical models of small watershed hydrology and applications, 335-367

Chu W, Gao X, Sorooshian S (2010) Improving the shuffled complex evolution scheme for optimization of complex nonlinear hydrological systems: application to the calibration of the Sacramento soil-moisture accounting model. Water Resour Res 46(9):W09530. doi:10.1029/2010WR009224

Dibike YB, Coulibaly P (2005) Hydrologic impact of climate change in the Saguenay watershed: comparison of downscaling methods and hydrologic models. J Hydrol 307:145-163

Duan Q, Sorooshian S, Gupta V (1992) Effective and efficient global optimization for conceptual rainfall-runoff models. Water Resour Res 28:1015-1031

Duan Q, Sorooshian S, Gupta VK (1994) Optimal use of the SCE-UA global optimization method for calibrating watershed models. J Hydrol 158:265-284

Dumedah G, Berg AA, Wineberg M, Collier R (2010) Selecting model parameter sets from a trade-off surface generated from the non-dominated sorting genetic algorithm-II. Water Resour Manag 24:4469-4489

Franchini M, Lamberti P (1994) A flood routing Muskingum type simulation and forecasting model based on level data alone. Water Resour Res 30(7):2183-2196

Füssel H-M, Klein RJ (2006) Climate change vulnerability assessments: an evolution of conceptual thinking. Clim Chang 75:301-329

Gill MK, Kaheil YH, Khalil A, McKee M, Bastidas L (2006) Multiobjective particle swarm optimization for parameter estimation in hydrology. Water Resour Res 42:W07417. doi:10.1029/2005WR004528

Guo S, Wang J, Xiong L, Ying A, Li D (2002) A macro-scale and semi-distributed monthly water balance model to predict climate change impacts in China. J Hydrol 268:1-15

Guo J, Zhou JZ, Zou Q, Liu Y, Song LX (2013) A novel multi-objective shuffled complex differential evolution algorithm with application to hydrological model parameter optimization. Water Resour Manag 27(8):2923-2946

IPCC (2001) Third assessment report-climate change 2001. IPCC/WMO/UNEP

Jiang T, Chen YD, Xu C-Y, X. C, Chen X, Singh VP (2007) Comparison of hydrological impacts of climate change simulated by six hydrological models in the Dongjiang Basin, South China. J Hydrol 336:316-333

Jiang Y, Liu C, Huang C, Wu X (2010) Improved particle swarm algorithm for hydrological parameter optimization. Appl Math Comput 217:3207-3215

Jiang Y, Li X, Huang C (2013) Automatic calibration a hydrological model using a master-slave swarms shuffling evolution algorithm based on self-adaptive particle swarm optimization. Expert Syst Appl 40(2):752-757

Jiang SH, Ren LL, Hong Y, Yang XL, Ma MW, Yuan F (2014) Improvement of multi-satellite real-time precipitation products for ensemble streamflow simulation in a middle latitude basin in south China. Water Resour Manag 28(8):2259-2278

Joseph JF, Guillaume JHA (2013) Using a parallelized MCMC algorithm in R to identify appropriate likelihood functions for SWAT. Environ Model Softw 46:292-298 
Kaini P, Artita K, Nicklow JW (2012) Optimizing structural best management practices using SWAT and genetic algorithm to improve water quality goals. Water Resour Manag 26:1827-1845

Li JZ, Feng P (2009) Trend ananlysis of runoff generation characteristics of Luanhe River Basin. J Arid Land Resour Environ 23(8):79-85 (in Chinese)

Li H, Zhang Y, Chiew FHS, Xu S (2009) Predicting runoff in ungauged catchments by using Xinanjiang model with MODIS leaf area index. J Hydrol 370:155-162

Liu CM, Wang GT (1980) The estimation of small-watershed peak flows in China. Water Resour Res 16(5):881886

Liu CM, Zheng HX, Wang ZG (2006) Distributed simulation of catchment water cycle. Yellow River Conservancy Press, Zhengzhou, China

Liu C, Wang Z, Zheng H, Zhang L, Wu X (2008) Development of hydro-informatic modelling system and its application. Sci China Ser Technol Sci 51:456-466

Liu LL, Fischer T, Jiang T, Luo Y (2013) Comparison of uncertainties in projected flood frequency of the Zhujiang River, South China. Quatern Int 304:51-56

Lu E, Takle ES, Manoj J (2010) The relationships between climatic and hydrological changes in the Upper Mississippi River Basin: A SWAT and multi-GCM study. J Hydrometeorol 11:437-451

Mengistu D, Sorteberg A (2012) Sensitivity of SWAT simulated streamflow to climatic changes within the Eastern Nile River basin. Hydrol Earth Syst Sci 16:391-407

Merritt WS, Alila Y, Barton M, Taylor B, Cohen S, Neilsen D (2006) Hydrologic response to scenarios of climate change in sub watersheds of the Okanagan basin, British Columbia. J Hydrol 326:79-108

Miller NL, Bashford KE, Strem E (2003) Potential impacts of climate change on California hydrology. J Am Water Resour Assoc 39:771-784

Muzik I (2002) A first-order analysis of the climate change effect on flood frequencies in a subalpine watershed by means of a hydrological rainfall-runoff model. J Hydrol 267:65-73

Peng D, Xu Z (2010) Simulating the Impact of climate change on streamflow in the Tarim River basin by using a modified semi-distributed monthly water balance model. Hydrol Process 24:209-216

Samadi S, Carbone GJ, Mahdavi M, Sharifi F, Bihamta MR (2013) Statistical downscaling of river runoff in a semi arid catchment. Water Resour Manag 27(1):117-136

Shi Y, Liu H, Fan M, Huang J (2013) Parameter identification of RVM Runoff forecasting model based on improved particle swarm optimization, advances in swarm intelligence. Springer, pp. 160-167

Shin MJ, Guillaume JH, Croke BF, Jakeman AJ (2013) Addressing ten questions about conceptual rainfallrunoff models with global sensitivity analyses in R. J Hydrol 503:135-152

Singh P, Arora M, Goel NK (2006) Effect of climate change on runoff of a glacierized Himalayan basin. Hydrol Process 20:1979-1992

Van Griensven A, Francos A, Bauwens W (2002) Sensitivity analysis and auto-calibration of an integral dynamic model for river water quality. Water Sci Technol 45:325-332

Varis O, Kajander T, Lemmelä R (2004) Climate and water: from climate models to water resources management and vice versa. Clim Chang 66:321-344

Vicuna S, Dracup J (2007) The evolution of climate change impact studies on hydrology and water resources in California. Clim Chang 82:327-350

Vrugt JA, Gupta HV, Bastidas LA, Bouten W, Sorooshian S (2003a) Effective and efficient algorithm for multiobjective optimization of hydrologic models. Water Resour Res 39:1214. doi:10.1029/2002WR001746

Vrugt JA, Gupta HV, Bouten W, Sorooshian S (2003b) A shuffled complex evolution metropolis algorithm for optimization and uncertainty assessment of hydrologic model parameters. Water Resour Res 39:1201. doi: 10.1029/2002WR001642

Wang QJ (1991) The genetic algorithm and its application to calibrating conceptual rainfall-runoff models. Water Resour Res 27:2467-2471

Wang QJ (1997) Using genetic algorithms to optimise model parameters. Environ Model Softw 12:27-34

White ED, Easton ZM, Fuka DR, Collick AS, Adgo E, McCartney M, Awulachew SB, Selassie YG, Steenhuis TS (2011) Development and application of a physically based landscape water balance in the SWAT model. Hydrol Process 25:915-925

Wu Y, Liu S, Gallant AL (2012) Predicting impacts of increased CO2 and climate change on the water cycle and water quality in the semiarid James River Basin of the Midwestern USA. Sci Total Environ 430:150-160

Xie ZH, Su FG, Liang X, Zeng QC (2003) Applications of a surface runoff model with Horton and Dunne runoff for VIC. Adv Atomospheric Sci 20(2):165-172

$\mathrm{Xu}$ C-Y (2000) Modelling the effects of climate change on water resources in central Sweden. Water Resour Manag 14:177-189

Xu C-Y, Widén E, Halldin S (2005) Modelling hydrological consequences of climate change-progress and challenges. Adv Atmos Sci 22:789-797

Xu ZX, Zhao FF, Li JY (2009) Response of streamflow to climate change in the headwater catchment of the Yellow River basin. Quat Int 208:62-75 
Yuan F, Xie ZH, Xia J (2005) Simulating hydrologic changes with climate change scenarios in the Haihe River Basin. Pedosphere 15:595-600

Zhan CS, Zeng SD, Jiang SS, Wang XH, Ye W (2014) An integrated approach for partitioning the effect of climate change and human activities on surface runoff. Water Resour Manag 28(11):3843-3858

Zhang Y, Chiew FHS (2009) Relative merits of different methods for runoff predictions in ungauged catchments. Water Resour Res 45, doi: 10.1029/2008WR007504

Zhang X, Srinivasan R, Hao E (2007) Predicting hydrologic response to climate change in the Luohe River basin using the SWAT model. Trans ASABE 50:901-910

Zhang X, Srinivasan R, Zhao K, Liew MV (2009) Evaluation of global optimization algorithms for parameter calibration of a computationally intensive hydrologic model. Hydrol Process 23:430-441

Zhao R (1992) The Xinanjiang model applied in China. J Hydrol 135:371-381

Zhao RJ, Liu XR, Singh VP (1995) The Xinanjiang model. Comput Models Watershed Hydrol, 215-232

Zuo DP, Xu ZX, Wu W, Zhao J, Zhao FF (2014) Identification of streamflow response to climate change and human activities in the Wei River Basin, China. Water Resour Manag 28(3):833-8551 